\title{
Prevention and management of scarring after thermal injury
}

\author{
Joshua Wong', Weber Lin ${ }^{2}$, Jie Ding ${ }^{2}$, Edward E. Tredget ${ }^{1,2}$ \\ 'Wound Healing Research Group, Department of Surgery, University of Alberta, Edmonton, Alberta T6G 2S2, Canada. \\ ${ }^{2}$ Division of Plastic and Reconstructive Surgery and Critical Care, Department of Surgery, University of Alberta, Edmonton, \\ Alberta T6G 2S2, Canada.
}

Correspondence to: Dr. Edward E. Tredget, Division of Plastic and Reconstructive Surgery and Critical Care, Department of Surgery, University of Alberta, 8440-112 Street, Edmonton, Alberta T6G 2S2, Canada. E-mail: etredget@ualberta.ca

How to cite this article: Wong J, Lin W, Ding J, Tredget EE. Prevention and management of scarring after thermal injury. Plast Aesthet Res 2021;8:9. http://dx.doi.org/10.20517/2347-9264.2020.171.

Received: 26 Aug 2020 First Decision: 9 Dec 2020 Revised: 22 Dec 2020 Accepted: 6 Jan 2021 Published: 28 Jan 2021

Academic Editors: Alexis Desmoulière, Raúl González-García Copy Editor: Monica Wang Production Editor: Xi-Jun Chen

\begin{abstract}
Survival from burn injury has improved considerably over the past two decades such that the quality of life of the victim of thermal injuries has become a major concern. Severe proliferative scarring or hypertrophic scarring (HTS) is an all too frequent complication of burn wound healing that severely compromises quality of life for surviving burn victims. Prevention of such scarring in burn patients involves better understanding of the pathophysiology of scar formation, development of newer methods for determining depth of burn injury and earlier and advanced surgical interventions. Many established and evolving novel treatments for HTS in patients after thermal injury exist and include antifibrotic pharmaceuticals and cellular-based therapies as reviewed herein.
\end{abstract}

Keywords: Thermal injury, hypertrophic scarring, transforming growth factor- $\beta$, fibrocytes, macrophages, scar prevention

\section{INTRODUCTION}

The World Health Organization estimates that over 180,000 deaths result annually from fire-related burns ${ }^{[1]}$, with low- and middle-income countries disproportionately affected. In North America, more than 400,000 cases of thermal injury occur each year, where 40,000 require hospitalization for long durations and require multiple reconstructive procedures ${ }^{[2]}$. In a majority of cases of thermal injury, functionally debilitating hypertrophic scarring (HTS) will develop and lead to long-term complications such as chronic pain,

cc) (i) (C) The Author(s) 2021. Open Access This article is licensed under a Creative Commons Attribution 4.0 International License (https://creativecommons.org/licenses/by/4.0/), which permits unrestricted use, sharing, adaptation, distribution and reproduction in any medium or format, for any purpose, even commercially, as long as you give appropriate credit to the original author(s) and the source, provide a link to the Creative Commons license, and indicate if changes were made. 
stiffness and aesthetic deformity. The psychologic consequences of scars in recovering burn patients can be severe and disabling, particularly where cosmetically sensitive regions are injured, making any efforts to prevent scars and deformity after burn injury very important considerations in their clinical care ${ }^{[3]}$.

\section{EPIDEMIOLOGY OF SCARRING AFTER BURN INJURY}

Despite advances in burn wound depth assessment and critical care management of the burn patients, a recent systematic review shows that the prevalence of HTS after burn injury is still strikingly high at $32 \%-72 \%{ }^{[4]}$. Surprisingly, the incidence of HTS after surgical intervention in burn injury can be as high as $70 \%{ }^{\left[{ }^{5}\right]}$. A study of prospective burn patients requiring treatment, whether operative or non-operative, involving anatomic joints showed that non-operative approaches restored normal range of motion by 9 months. However, $20 \%$ of those who received operative management, most commonly skin grafting over the joint involved, still had persistent joint contracture at 12 months post-injury ${ }^{[6]}$.

When looking at the risk factors that lead to pathologic scarring after burn injury, the exhaustive multivariate review of 703 patients by Gangemi et al. ${ }^{[7]}$ reveals that female sex, younger age, burn sites on the neck or upper limbs, multiple surgical procedures, and meshed skin grafts were independent risk factors that contributed to increased incidence. In pediatric burn injury, Rotatori et al ${ }^{[8]}$ reviewed 237 patients and found an astounding 64\% with HTS. Specific risk factors for HTS included Hispanic ethnicity, increased total burn area, increased depth of injury, and increased percentage of burn requiring skin autografting. Risk factors involved in developing donor site HTS were increased time of epithelialization, increased depth of skin harvest, and thigh as the anatomical donor ${ }^{[8]}$.

It is important to realize that the spectrum of scarring can range from pathologic to hypertrophic with an associated contracture. Also, HTS can be associated with other comorbidities such as chronic pain and pruritus, especially in patients who receive skin autografting procedures ${ }^{[9]}$.

Traditionally, post-burn scarring has been assessed and measured with objective means based on clinician assessment. Recent studies suggest that a substantial portion of the morbidity from post-burn HTS requires patient self-assessment and pain scoring. Goverman et al ${ }^{[10]}$ suggests that even 2 years after initial injury, burn patients report as high as $80 \%$ incidence of raised or thick scars and an increase in symptoms related to HTS, such as dry or fragile skin, scars restricting range of motion and scar pain or itch. A review of longterm outcomes using the Burn Specific Health Scale Brief shows that even ten years post-injury, patients are still struggling with heat sensitivity and scar stiffness affecting work and that a significantly higher incidence of these issues occurs in females ${ }^{[11]}$.

\section{PATHOPHYSIOLOGY OF HTS AFTER BURN INJURY}

It is now well recognized that burn injury into the deep or reticular dermis is most commonly associated with the development of HTS. Fibroblasts isolated from the deep dermis possess many of the features typical of similar cells explanted from $\operatorname{HTS}^{[12]}$ [Table 1].

In addition, single cell isolation has recovered unique populations of fibroblasts that contribute to scar formation in the perivasculature of the skin and deeper structures ${ }^{[13]}$. A clinical study in human skin with a progressively deeper incision injury demonstrates the development of HTS in lateral hip skin once the injury exceeds $0.56 \mathrm{~mm}$ or more than one-third of the thickness of the human skin ${ }^{[14]}$. Activation of deep dermal fibroblasts through toll-like receptors (TLRs) ${ }^{[15]}$ leads to prolonged release of inflammatory cytokines including interleukin (IL)-1, tumor necrosis factor (TNF)- $\alpha$ and interferon (IFN) $-\gamma$, which chemoattracts inflammatory monocytes into slowly healing wounds. 
Table 1. Comparison of the characteristics of human dermal fibroblasts derived from normal skin, hypertrophic scars and deep dermis

\begin{tabular}{lccc}
\hline & Normal fibroblasts & HTS fibroblasts & Deep dermal fibroblasts \\
\hline Cell size & + & + & ++ \\
Proliferation rate & ++ & ++ & + \\
Collagen synthesis & + & ++ & ++ \\
Collagenase activity & ++++ & + & + \\
$\alpha$-SMA expression & + & +++ & ++ \\
Collagen gel contraction & + & +++ & ++ \\
TGF- $\beta$ & + & ++ & +++ \\
TGF- $\beta$ type Il receptor & + & +++ & +++ \\
CTGF & + & +++ & +++ \\
Osteopontin & + & + & + \\
Decorin synthesis & ++++ & + & + \\
Fibromodulin synthesis & ++++ & +++ & +++ \\
Biglycan synthesis & + & +++ & +++ \\
Versican synthesis & + & +++ & ++ \\
TLRs & + & & ++ \\
\hline
\end{tabular}

$\alpha$-SMA: alpha smooth muscle actin; TGF- $\beta$ : transforming growth factor beta; CTGF: connective tissue growth factor; TLR: toll-like receptor; HTS: hypertrophic scarring.

The systemic immunologic response to major burn injury leading to severe HTS includes a polarized T-helper cell 2 environment ${ }^{[1,17]}$, which also promotes the differentiation of blood-borne fibrocytes ${ }^{[18]}$, secreting extracellular matrix (ECM) proteins, proteases, and fibrotic cytokines, including transforming growth factor- $\beta$ (TGF)- $\beta$. This response to burn injury persists for up to 1 year after burn injury, such that reconstruction in patients with large burns and limited skin donor sites is best delayed where possible, until resolution of the systemic inflammatory response. Major burn injury contributes circulating monocytes to the healing wound in response to chemokines, including chemokine ligand 12 (CXCL-12; also termed stromal cell-derived factor 1) released by activated fibroblasts, where binding to chemokine receptor CXCR-4 leads to continued inflammation ${ }^{[19]}$. Chronic release of TGF- $\beta$ in the wound tissues results in fibroblast proliferation, collagen and proteoglycan synthesis and excessive matrix synthesis. The morphology of the healing matrix is distorted by increased collagen I and III but also abnormal proteoglycans including versican, aggrecan and biglycan, which causes a fibrocartilaginous transformation of the healing skin and reduces remodeling ${ }^{[20]}$. Typically, hypertrophic scars are deficient in decorin, a small leucine-rich proteoglycan that binds collagen leading to tightly packed fibers and fiber bundles seen in normal skin, where it is produced in abundance by normal fibroblasts ${ }^{[21]}$. However, both HTS fibroblasts and deep dermal fibroblasts produce little decorin partly because of small inhibitory RNAs that downregulate decorin gene transcription ${ }^{[22]}$.

Ultimately, limiting inflammation in the skin and extension of the depth of injury after thermal injury becomes critical in preventing a superficial wound, which heals with minimal scar formation such as the non-scarred region of the scratch injury, from converting into a deeper dermal injury and the inherent scar formation as a result ${ }^{[14]}$.

\section{PREVENTION OF SCARRING AFTER THERMAL INJURY}

Clinical assessment of the depth of burn wounds is well recognized to be difficult and accurate in only 65\%-70\% of cases even when performed by an experienced burn surgeon, partly because of the evolving inflammatory response to the injured tissue, which may lead to deepening of the wound over the first several days after injury ${ }^{[23]}$. A number of clinical management features become important in preventing extension of the original burn injury into the deep dermal region of the skin ${ }^{[24]}$. Prevention of burn scarring involves the understanding that, beyond a critical depth, activated deep dermal fibroblasts of specific lineage with fibrogenic potential will lead to HTS. Therefore, accurate determination of burn 
depth is paramount and can be achieved with serial examination aided by objective instruments ${ }^{[25]}$ to avoid unnecessary surgery. Despite the creation of a new wound and possible scar at the donor site, skin graft resurfacing is indicated for deep dermal burns to avoid HTS, particularly in critical cosmetic regions such as the face ${ }^{[26]}$. Decreased time to epithelialization is proportionately related to the depth of injury and also the incidence of developing HTS. Factors involved in ensuring minimal time to epithelialization are preventing wound conversion by avoiding over-resuscitation, preventing secondary wound infection, avoiding chemical toxicity from topical wound agents, and accurate surgical decision-making for deep wounds only ${ }^{[27-29]}$. The major challenge in burn depth assessment is in partial-thickness wounds where clinical evaluation by experienced clinicians is often inaccurate, in part because of the evolving inflammation that progresses in deep dermal wounds in the zone of stasis ${ }^{[30,31]}$. Thus, new instruments to aid as adjuncts to evaluate burn depth are becoming useful tools. One such tool includes the laser Doppler imaging (LDI) system, which evaluates microvascular dermal perfusion ${ }^{[32,33]}$. LDI is performed between 48 hours and 5 days after burn injury and has an accuracy ranging from $90 \%$ to $97 \%$, compared with $52.5 \%$ to $71.4 \%$ with clinical evaluation ${ }^{[34-36]}$. LDI has a positive predictive value for burns that will not heal within 14 to 21 days of $85.1 \%$ to $98 \%$ and is accurate and noninvasive; however, sedation is often required for burns in young children, where LDI likely has its greatest applicability. Commercial videos illustrating LDI application are available online ${ }^{[37]}$ with newer iterations of the technology that have quicker response time, decreased lag time and higher utility in specialized populations such as pediatrics and the elderly. In a recent meta-analysis of 321 publications related to burn depth assessment with LDI, Shin and Yi concluded that LDI is an accurate measurement tool when combined with careful clinical assessment of deep burn wounds ${ }^{[38]}$.

Other modalities to distinguish burn depth at early time points have been investigated, including thermography ${ }^{[39]}$, ultrasonography ${ }^{[40]}$, nuclear magnetic resonance ${ }^{[41]}$, near-infrared spectroscopy imaging, and confocal microscopy ${ }^{[42]}$. An emerging technology in microvascular surgery that overlaps with indeterminate burn depth assessment is in indocyanine green (ICG) angiography. In a prospective, multicenter triple-blinded study, ICG was shown to have higher accuracy in indeterminate burn wound assessment compared to clinical assessment and 100\% sensitivity and specificity with tissue biopsy as a gold standard ${ }^{[43]}$. In the age of smartphone use in medicine and surgery, some centers have applied infrared thermography from a handheld device for assessing burn wounds and shown more than $90 \%$ overlap of estimation of salvageable tissue margins when compared to ICG angiography ${ }^{[44]}$. To date, however, these other techniques have gained only modest application in clinical practice because they may require expensive equipment, standardized training, and controlled environmental conditions during assessment.

Operating early on deep and full-thickness burns to prevent HTS is an approach useful for clearly deeper burn injuries identified by serial clinical examination of wound depth, scanning laser Doppler measurement and the time to epithelialization. In deep burns of the face, a better cosmetic result is achieved by surgical intervention and planned skin grafting using carefully selected donor tissues. Improved cosmetic outcome is achieved in these cases and is illustrated by less HTS in regions of skin-grafted tissues as compared to wounds that healed over prolonged intervals in the same patient ${ }^{[45]}$. Accurate wound depth estimation is paramount for serial assessment in particular areas that may be left longer to heal such as the face and glabrous surfaces. As such, serial assessment of epithelialization can be fraught with error when burn units have changes of attending physicians every 1 to 2 weeks. A recent study showed that sequential highresolution photo assessment had higher intra-class correlation to digital image analysis than serial clinical wound assessments ${ }^{[4]}$. As more centers transition to electronic medical records, the use of daily or regular photo documentation will assist in accurate assessment of the progression of healing.

\section{NON-OPERATIVE MANAGEMENT OF BURN SCARS}

Prior to complete burn HTS maturation, several therapeutic options are currently implemented to halt the progression of HTS. These options include scar massage, pressure garment therapy and topical silicone 
gel sheeting or silicone spray. The most common and least resource-intensive therapy is scar massage, and preliminary evidence suggests that scar massage upwards of 20-30 min per day can decrease scar height, vascularity, pain and pruritis and improve scar pliability in burn HTS. However, evidence-based guidelines are not well defined as larger controlled clinical trials are required ${ }^{[47]}$. Most compiled highquality evidence suggests that compression garment therapy at normal compression (20 mmHg or greater) can improve scar thickness and probably decreases scar redness. Silicone therapy shows positive results in improving scar pliability and redness ${ }^{[48]}$. Unfortunately, the studies are small in number and do not use accurate or standardized objective measurements of scar for outcome assessment and ultimately do not delineate "indications, duration and efficacy" of treatment ${ }^{[49]}$. There is evidence to suggest that no significant difference exists between compression and silicone therapy alone or in combination ${ }^{[50,51]}$. In fact, a similarity in efficacy can be seen between topical silicone spray and silicone gel sheeting but with less side effects in the silicone spray group compared to gel sheeting, which more commonly leads to skin maceration and contact dermatitis. This could have a large impact on treatment as compliance with silicone spray is much better than gel sheeting, especially in cosmetic areas such as the face, or when $23 \mathrm{~h} /$ day of more uncomfortable compression garment therapy is required.

Conventional treatments for HTS after thermal injury include corticosteroid injections, laser therapy, or surgery including scar release and skin resurfacing ${ }^{[52]}$.

Pulsed-dye laser and fractional carbon dioxide laser have shown promise as an adjunct to established treatments for burn scar treatment. Pulsed-dye laser therapy selectively targets hemoglobin at the 585-nm wavelength, making it effective in hypervascular immature burn scars to reduce erythema. Using pulseddye and fractional carbon dioxide lasers, Hultman et al. ${ }^{[53]}$ demonstrated significant improvements in before-and-after burn scar scale scores and patient-reported outcomes. Ablative lasers such as the neodymium:yttrium-aluminum-garnet laser have been effective in contact mode, where 102 scar patients treated every 3 to 4 weeks for 1 year demonstrated significant improvements overall ${ }^{[54]}$. Unfortunately, scar recurrence developed in the upper chest, arm, and back areas, particularly if residual erythema and induration persisted following therapy. Thus, although laser treatment of post-burn HTS offers a new, potentially transformative approach to difficult scar challenges, further objective controlled trials are required $^{[55]}$.

\section{OPERATIVE REVISION OF BURN SCARS: NEW APPROACHES}

Burn reconstruction may be accomplished with the following: contracture release; scar excision and resurfacing; local transposition, rotation, and advancement flaps; tissue expansion; or distant axial flap, as well as with the use of skin substitutes such as Integra ${ }^{\mathrm{TM}[56,57]}$. Despite the requirements for greater operative times and specialized training and equipment, surgeons can also offer significant reconstruction advantages for burn patients through the use of reconstructive microsurgery. Acutely, free flaps may be used for limb salvage or defect coverage, permitting preservation of exposed vital structures such as nerves, tendons, vessels, or bone, often in high-voltage electrical burns, to avoid limb amputation ${ }^{[58]}$.

Microvascular free flaps are also used in reconstruction of joint contractures and HTS when injured or deficient regional tissue precludes local flaps, skin grafts, or tissue expansion, where success rates for free flap transfer in burn reconstruction range from $78 \%$ to $96 \%{ }^{[59]}$. Excessive free flap bulk is averted by the use of thinner fasciocutaneous flaps such as the anterolateral thigh ${ }^{[60]}$ or parascapular ${ }^{[61]}$ flaps in the head and neck region ${ }^{[62]}$ and thin fascial flaps such as the temporoparietal fascial or serratus fascial flaps in the dorsum of the hand, which offer better color, thickness, and texture match ${ }^{[63]}$. 


\section{POTENTIAL NOVEL TREATMENTS OF HTS AFTER BURN INJURY IN THE FUTURE}

Splinting, pressure garments and silicone gel physical therapies are conventional treatments of HTS after burn injury but are time-consuming and not always suitable for HTS in specific regions such as the hands, feet and facial areas. Topically applied pharmacological agents such as antimicrobial creams have been traditionally used to prevent infection, and new enzymatic debridement agents are available for removal of necrotic wound eschar. However, high level scientific support for topical therapies in the form of controlled multicenter trials is difficult and expensive to achieve. Despite these complexities, ongoing research into the basic pathophysiology of fibroproliferative scars is yielding newer, novel strategies directed against specific molecules.

\section{Strategies to manipulate TGF- $\beta$ in the healing wound}

TGF- $\beta$ expression is involved in many wound healing processes including inflammation, angiogenesis, reepithelialization, ECM synthesis, and wound remodeling. TGF- $\beta$ promotes myofibroblast proliferation, differentiation and wound contraction in many fibrotic diseases ${ }^{[64,65]}$. Fetal wound healing studies seeking to exploit the specific features of regenerative healing of the fetus in utero, have identified the specific TGF- $\beta$ isoform TGF- $\beta 3$ as an important cytokine present in the regenerating scarless fetal wound environment as opposed to TGF- $\beta 1$ and TGF- $\beta 2$ expressed in adults, where scarring is the inevitable consequence of adult wounds ${ }^{[64,65]}$. Unfortunately, despite encouraging preclinical evidence, current clinical trials on antagonizing the effects of TGF- $\beta$ have been disappointing. For example, Juvista (Renovo, UK), a commercially developed recombinant form of TGF- $\beta 3$ product, which demonstrated positive results in animal models and early phase human trials, was unsuccessful in significantly improving scar outcomes in a phase III trial ${ }^{[6,66]}$. Similarly, an inhibitor of the mannose- 6 phosphate receptor for TGF- $\beta 1 /$ TGF- $\beta 2$, Juvidex (Renovo, UK) also was unsuccessful in a phase II trial ${ }^{[64]}$. TGF- $\beta$ has important roles in burn wound healing and during HTS development. However, substantial blockage of TGF- $\beta$ receptors to prevent fibrosis using recombinant human antibodies, can delay or prevent wound healing leading to chronic, non-healing wounds ${ }^{[65]}$. Similarly, treatment of patients with systemic sclerosis with recombinant human antibodies to neutralize TGF- $\beta 1$ did not improve efficacy over controls during phase I/II trials ${ }^{[64]}$. Thus, although strategies to manipulate TGF- $\beta$ continues to be an important potential therapeutic opportunity in fibrotic diseases, newer approaches to modulating TGF- $\beta$ expression appear to be required.

\section{Potential role of interleukins in burn wound healing}

After burn injury, neutrophils and macrophages release inflammatory growth factors including IL-1, $-2,-6$, -8 and others as well as IFN- $\gamma$ and TNF- $\alpha^{[68]}$. IL-10 has been shown to reduce inflammation by sequestering IL- 6 or IL-8 and by reducing inflammatory T-cell cytokine production. Administering Prevascar (Renovo, UK), a recombinant human IL-10 product, intradermally during early wound healing ${ }^{[68]}$ improved scar healing in human patients during phase I/II trials ${ }^{[64]}$. Other clinical trials with recombinant IL-10 to potentially combat various inflammatory diseases ${ }^{[68]}$ are ongoing. However, a phase II clinical trial ${ }^{[69]}$ conducted with IL-10 demonstrated no effectiveness in reducing scar formation in humans of continental African ancestral origin ${ }^{[68,70]}$. IL-2 may also contribute to the resolution of inflammation and improve the strength of the healed wound. Unfortunately, IL-2 clinically causes systemic inflammation and thus has a narrow therapeutic window ${ }^{[71]}$.

\section{Agents that modulate mechanical stress in wounds}

Mechanical stress during wound healing facilitates fibrosis via cellular activation that stimulates cytokine release and promotes $\mathrm{HTS}^{[72,73]}$. New polymer-stress shielding devices to reduce mechanical stress to modulate local biomechanics, have been used to minimize scar development by off-loading mechanical forces, reducing mechanical stress imposed upon healing incisions ${ }^{[72,74]}$ in high-tension body locations which are susceptible to developing HTS such as the central chest, shoulders, knees, ankles, and/or the back ${ }^{[52]}$. However, physical devices that reduce wound tension cannot be used easily on excisional 
wounds, burn injuries, and wounds that formed in convex surfaces such as the facial area. However, noninvasive drugs that target key mechanical signal transduction pathways involved in converting mechanical stress to intracellular biological signals have been developed ${ }^{[75,76]}$ and are at the early stage of pre-clinical development.

\section{Stem cells and other cellular therapies}

Stem cells and cultured epithelial cells have potential benefit in severe burn injuries when used as wound closure techniques or anti-scarring biological agents in addition to standard skin grafting techniques. The efficacy and biosafety of many of these approaches are incompletely understood and as a result the technology is tightly regulated ${ }^{[77]}$.

Although allogenic epithelial cells stimulate an immunologic rejection response, allogeneic cells as well as autologous approaches have been developed using cells derived from skin and other tissues for burn wound management ${ }^{[77]}$. Cultured epithelial allografts have been used for temporary coverage of acute burns as a bridge to eventual cultured epithelial autografting. Cost-utility analysis suggested that they facilitate healing in partial-thickness burns ${ }^{[78]}$. Cultured epithelial autografts may speed wound closure when combined with meshed skin grafts ${ }^{[78]}$. Fibroblasts added to dermal scaffolds may produce ECM proteins and growth factors that improve healing ${ }^{[77,79]}$. Keratinocyte stem cells regulate epithelial stratification and regeneration of skin appendages and hair follicles ${ }^{[77,80]}$ and are beginning to be tested in burn wound management ${ }^{[81]}$, as along with undifferentiated stem cells and progenitor cells ${ }^{[77]}$. Mesenchymal stem cells (MSC) administered systemically and locally have been shown to speed wound healing and regeneration and minimize scarring ${ }^{[77,82,83]}$. Induced pluripotent stem cells from human embryonic stem cells may also be useful as temporary skin substitutes for burn patients with large surface area burns. However, human embryonic cell research is associated with ethical issues and safety concerns yet to be resolved. MSC may be useful to correct defective granulation tissue formation and to heal chronic wounds ${ }^{[84]}$. Macrophage differentiation in granulation tissue formation initiates regenerative M2 polarization, fibroblast proliferation and differentiation with wound contraction, blood vessel formation, and matrix deposition. After burn injury, impairment of granulation tissue formation can result in delayed wound healing and HTS. The primary effect of MSC appears to be due to the release of growth factors into the wound and their paracrine effects on nearby resident cells, rather than engrafting and transdifferentiating into host tissue, thereby accelerating wound healing and reducing scarring. MSC sense and re-establish a reparative and regenerative local environment in response to local conditions in the wound. These environmental molecules include pathogen-associated molecular patterns (PAMPs) and/or damage-associated molecular patterns (DAMPs), which activate TLRs, or growth factors and/or inflammatory mediators and their respective receptors. Because MSC possess the unique capacity to sense and restore regenerative healing in wounds, they may be ideal therapeutic cells that adapt to changes in the local environment of disordered wounds.

Perivascular dermal MSC comprise about $0.3 \%-2.5 \%$ of total mesenchymal cells in the skin ${ }^{[85,86]}$. Quantitatively, MSC are not able to correct the disordered wound environment, but when delivered in higher therapeutic numbers, they can restore wound repair and regeneration in preclinical studies to date. Current data demonstrate the unique responses of therapeutically administered MSC in adapting to specific healing wounds; however, the inability of endogenous MSC in these settings to heal the wounds is poorly understood in part because of the lack of specific markers for MSC in vivo.

\section{Challenges to the evaluation of new antifibrotic treatments}

Experimental treatment for hypertrophic scarring after burn injury includes IFN- $\alpha 2 b$, an anti-fibrotic T-helper cell cytokine that significantly improves scar remodeling and normalizes TGF- $\beta^{[18,87,88]}$. New promising pharmacologic agents include topical imiquimod, calcium channel blockers, tacrolimus, 
5-fluorouracil, pirfenidone, and bleomycin, as well as more experimental biological agents including IL-10, inhibitory microRNA against TGF- $\beta$, and peptide inhibitors of CXCR4 as potential future therapies ${ }^{[12,19,89]}$.

\section{Development of new scarring models and outcome measures}

Unfortunately, designing clinical trials of antifibrotic agents is difficult due to the inter-individual characteristics, variable severity and depth of injury between and within subjects and sensitivity and objectivity of outcome measurements. As a result, new approaches have been developed by standardized scratch wounds where progressively increasing wound depth from one end to the other leads to wounds that heal with HTS at the deep end and regenerative non-proliferative scars at the superficial end ${ }^{[14,90,91]}$. This approach controls for variation between individuals when two scratches are created allowing for double-blinded, placebo-controlled studies. When coupled with patient- and observer-rated scar rating systems and more objective and sensitive outcome assessments including colorimetry and scar volume measurements with ultrasound and scar pliability instruments, more accurate assessment of the benefits of new modalities to prevent and treat scars will be achieved.

\section{CONCLUSIONS}

HTS following burn injury remain a major cause of morbidity for thermally injured victims. Advances in clinical care coupled with improved understanding of the pathophysiology of fibroproliferative scarring as outlined herein will improve the management of burn patients in the future.

\section{DECLARATIONS}

\section{Authors' contributions}

Wrote the the manuscript: Wong J, Tredget EE

Edited the manuscript: Lin W

Provided original data: Ding J

\section{Availability of data and materials}

Not applicable.

\section{Financial support and sponsorship}

The authors were supported by the Firefighter's Burn Trust Fund of the University of Alberta.

\section{Conflicts of interest}

All authors declare that there are no conflicts of interest.

\section{Ethical approval and consent to participate}

Not applicable.

\section{Consent for publication}

Not applicable.

\section{Copyright}

(c) The Author(s) 2020.

\section{REFERENCES}

1. World Health Organization. Burns: Fact sheet. Available from: https://www.who.int/en/news-room/fact-sheets/detail/burns. [Last accessed on 10 Jul 2020]

2. Zhu Z, Ding J, Tredget EE. The molecular basis of hypertrophic scars. Burns Trauma 2016;4:2.

3. Sainsbury DC. Body image and facial burns. Adv Skin Wound Care 2009;22:39-44; quiz 45-6. 
4. Lawrence JW, Mason ST, Schomer K, Klein MB. Epidemiology and impact of scarring after burn injury: a systematic review of the literature. J Burn Care Res 2012;33:136-46.

5. Gauglitz GG, Korting HC, Pavicic T, Ruzicka T, Jeschke MG. Hypertrophic scarring and keloids: pathomechanisms and current and emerging treatment strategies. Mol Med 2011;17:113-25.

6. Schouten HJ, Nieuwenhuis MK, van Baar ME, van der Schans CP, Niemeijer AS, van Zuijlen PPM. The prevalence and development of burn scar contractures: a prospective multicenter cohort study. Burns 2019;45:783-90.

7. Gangemi EN, Gregori D, Berchialla P, et al. Epidemiology and risk factors for pathologic scarring after burn wounds. Arch Facial Plast Surg 2008;10:93-102.

8. Rotatori RM, Starr B, Peake M, et al. Prevalence and risk factors for hypertrophic scarring of split thickness autograft donor sites in a pediatric burn population. Burns 2019;45:1066-74.

9. Mauck MC, Shupp JW, Williams F, et al. Hypertrophic scar severity at autograft sites is associated with increased pain and itch after major thermal burn injury. J Burn Care Res 2018;39:536-44.

10. Goverman J, He W, Martello G, et al. The presence of scarring and associated morbidity in the Burn Model System National Database. Ann Plast Surg 2019;82:S162-8.

11. Chin TL, Carrougher GJ, Amtmann D, et al. Trends 10 years after burn injury: a Burn Model System National Database study. Burns 2018;44:1882-6.

12. Tredget EE, Levi B, Donelan MB. Biology and principles of scar management and burn reconstruction. Surg Clin North Am 2014;94:793815.

13. Driskell RR, Lichtenberger BM, Hoste E, et al. Distinct fibroblast lineages determine dermal architecture in skin development and repair. Nature 2013;504:277-81.

14. Dunkin CSJ, Pleat JM, Gillespie PH, Tyler MPH, Roberts AHN, McGrouther DA. Scarring occurs at a critical depth of skin injury: precise measurement in a graduated dermal scratch in human volunteers. Plast Reconstr Surg 2007;119:1722-32.

15. Wang J, Hori K, Ding J, et al. Toll-like receptors expressed by dermal fibroblasts contribute to hypertrophic scarring. J Cell Physiol 2011;226:1265-73.

16. Tredget EE, Yang L, Delehanty M, Shankowsky H, Scott PG. Polarized Th2 cytokine production in patients with hypertrophic scar following thermal injury. J Interferon Cytokine Res 2006;26:179-89.

17. Zhang M, Zhang S. T Cells in fibrosis and fibrotic diseases. Front Immunol 2020;11:1142.

18. Wang J, Jiao H, Stewart TL, Shankowsky HA, Scott PG, Tredget EE. Improvement in postburn hypertrophic scar after treatment with IFN-alpha2b is associated with decreased fibrocytes. J Interferon Cytokine Res 2007;27:921-30.

19. Ding J, Ma Z, Liu H, et al. The therapeutic potential of a C-X-C chemokine receptor type 4 (CXCR-4) antagonist on hypertrophic scarring in vivo. Wound Repair Regen 2014;22:622-30.

20. Scott PG, Dodd CM, Tredget EE, Ghahary A, Rahemtulla F. Chemical characterization and quantification of proteoglycans in human post-burn hypertrophic and mature scars. Clin Sci (Lond) 1996;90:417-25.

21. Scott PG, Dodd CM, Tredget EE, Ghahary A, Rahemtulla F. Immunohistochemical localization of the proteoglycans decorin, biglycan and versican and transforming growth factor-beta in human post-burn hypertrophic and mature scars. Histopathology 1995;26:423-31.

22. Kwan P, Ding J, Tredget EE. MicroRNA 181b regulates decorin production by dermal fibroblasts and may be a potential therapy for hypertrophic scar. PLoS One 2015;10:e0123054.

23. Monstrey S, Hoeksema H, Verbelen J, Pirayesh A, Blondeel P. Assessment of burn depth and burn wound healing potential. Burns 2008:34:761-9.

24. Kwan P, Desmoulière A, Tredget EE. Molecular and cellular basis of hypertrophic scarring. In: Total Burn Care.4th ed. Herndon, D.N., Ed.; W.B. Saunders: London, UK, 2012. pp. 495-505.

25. Stewart TL, Ball B, Schembri PJ, et al; Wound Healing Research Group. The use of laser Doppler imaging as a predictor of burn depth and hypertrophic scar postburn injury. J Burn Care Res 2012;33:764-71.

26. Fraulin FO, Illmayer SJ, Tredget EE. Assessment of cosmetic and functional results of conservative versus surgical management of facial burns. J Burn Care Rehabil 1996;17:19-29.

27. Tricklebank S. Modern trends in fluid therapy for burns. Burns 2009;35:757-67.

28. Kim DE, Phillips TM, Jeng JC, et al. Microvascular assessment of burn depth conversion during varying resuscitation conditions. $J$ Burn Care Rehabil 2001;22:406-16.

29. Cotter JL, Fader RC, Lilley C, Herndon DN. Chemical parameters, antimicrobial activities, and tissue toxicity of 0.1 and $0.5 \%$ sodium hypochlorite solutions. Antimicrob Agents Chemother 1985;28:118-22.

30. Jackson DM. The treatment of burns: an exercise in emergency surgery. Ann R Coll Surg Engl 1953;13:236-57.

31. Singh V, Devgan L, Bhat S, Milner SM. The pathogenesis of burn wound conversion. Ann Plast Surg 2007;59:109-15.

32. Jaskille AD, Ramella-Roman JC, Shupp JW, Jordan MH, Jeng JC. Critical review of burn depth assessment techniques: part II. review of laser Doppler technology. J Burn Care Res 2010;31:151-7.

33. Wang R, Zhao J, Zhang Z, Cao C, Zhang Y, Mao Y. Diagnostic accuracy of laser Doppler imaging for the assessment of burn depth: a meta-analysis and systematic review. J Burn Care Res 2020;41:619-25.

34. La Hei ER, Holland AJ, Martin HC. Laser Doppler imaging of paediatric burns: burn wound outcome can be predicted independent of clinical examination. Burns 2006;32:550-3.

35. Jeng JC, Bridgeman A, Shivnan L, et al. Laser Doppler imaging determines need for excision and grafting in advance of clinical judgment: a prospective blinded trial. Burns 2003;29:665-70. 
36. Park YS, Choi YH, Lee HS, et al. The impact of laser Doppler imaging on the early decision-making process for surgical intervention in adults with indeterminate burns. Burns 2013;39:655-61.

37. Moor Instruments Inc. Early and accurate assessment of burns. Available from: http://us.moor.co.uk/product/burn-assessment-burnassessment/286/o/41/video-channel. [Last accessed on 30 Nov 2015]

38. Shin JY, Yi HS. Diagnostic accuracy of laser Doppler imaging in burn depth assessment: Systematic review and meta-analysis. Burns 2016;42:1369-76.

39. Mladick R, Georgiade N, Thorne F. A clinical evaluation of the use of thermography in determining degree of burn injury. Plast Reconstr Surg 1966;38:512-8.

40. Iraniha S, Cinat ME, VanderKam VM, et al. Determination of burn depth with noncontact ultrasonography. $J$ Burn Care Rehabil 2000;21:333-8.

41. Koruda MJ, Zimbler A, Settle RG, et al. Assessing burn wound depth using in vitro nuclear magnetic resonance (NMR). J Surg Res 1986;40:475-81.

42. Altintas MA, Altintas AA, Knobloch K, Guggenheim M, Zweifel CJ, Vogt PM. Differentiation of superficial-partial vs. deep-partial thickness burn injuries in vivo by confocal-laser-scanning microscopy. Burns 2009;35:80-6.

43. Wongkietkachorn A, Surakunprapha P, Winaikosol K, et al. Indocyanine green dye angiography as an adjunct to assess indeterminate burn wounds: a prospective, multicentered, triple-blinded study. J Trauma Acute Care Surg 2019;86:823-8.

44. Xue EY, Chandler LK, Viviano SL, Keith JD. Use of FLIR ONE smartphone thermography in burn wound assessment. Ann Plast Surg 2018;80:S236-8.

45. Fraulin FO, Tredget EE. Subcutaneous instillation of donor sites in burn patients. Br J Plast Surg 1993;46:324-6.

46. Koetsier KS, Wong JN, Muffley LA, Carrougher GJ, Pham TN, Gibran NS. Prospective observational study comparing burn surgeons' estimations of wound healing after skin grafting to photo-assisted methods. Burns 2019;45:1562-70.

47. Ault P, Plaza A, Paratz J. Scar massage for hypertrophic burns scarring-a systematic review. Burns 2018;44:24-38.

48. Anthonissen M, Daly D, Janssens T, Van den Kerckhove E. The effects of conservative treatments on burn scars: a systematic review. Burns 2016;42:508-18.

49. Tredget EE, Shupp JW, Schneider JC. Scar management following burn injury. J Burn Care Res 2017;38:146-7.

50. Steinstraesser L, Flak E, Witte B, et al. Pressure garment therapy alone and in combination with silicone for the prevention of hypertrophic scarring: randomized controlled trial with intraindividual comparison. Plast Reconstr Surg 2011;128:306e-13e.

51. Wiseman J, Ware RS, Simons M, et al. Effectiveness of topical silicone gel and pressure garment therapy for burn scar prevention and management in children: a randomized controlled trial. Clin Rehabil 2020;34:120-31.

52. Kwan PO, Tredget EE. Biological principles of scar and contracture. Hand Clin 2017;33:277-92.

53. Hultman CS, Edkins RE, Wu C, Calvert CT, Cairns BA. Prospective, before-after cohort study to assess the efficacy of laser therapy on hypertrophic burn scars. Ann Plast Surg 2013;70:521-6.

54. Koike S, Akaishi S, Nagashima Y, Dohi T, Hyakusoku H, Ogawa R. Nd:YAG laser treatment for keloids and hypertrophic scars: an analysis of 102 cases. Plast Reconstr Surg Glob Open 2015;2:e272.

55. Poetschke J, Dornseifer U, Clementoni MT, et al. Ultrapulsed fractional ablative carbon dioxide laser treatment of hypertrophic burn scars: evaluation of an in-patient controlled, standardized treatment approach. Lasers Med Sci 2017;32:1031-40.

56. Orgill DP, Ogawa R. Current methods of burn reconstruction. Plast Reconstr Surg 2013;131:827e-36e.

57. Integra Dermal Regeneration Template [package insert on the internet]. Princeton, NJ: Integra LifeSciences; 2012. Available from: https:// www.integralife.com/file/general/1453795605-1.pdf. [Last accessed on 12 Jul 2020]

58. Sauerbier M, Ofer N, Germann G, Baumeister S. Microvascular reconstruction in burn and electrical burn injuries of the severely traumatized upper extremity. Plast Reconstr Surg 2007;119:605-15.

59. Platt AJ, McKiernan MV, McLean NR. Free tissue transfer in the management of burns. Burns 1996;22:474-6.

60. Yang JY, Tsai FC, Chana JS, Chuang SS, Chang SY, Huang WC. Use of free thin anterolateral thigh flaps combined with cervicoplasty for reconstruction of postburn anterior cervical contractures. Plast Reconstr Surg 2002;110:39-46.

61. Angrigiani C. Aesthetic microsurgical reconstruction of anterior neck burn deformities. Plast Reconstr Surg 1994;93:507-18.

62. Parrett BM, Pomahac B, Orgill DP, Pribaz JJ. The role of free-tissue transfer for head and neck burn reconstruction. Plast Reconstr Surg 2007;120:1871-8.

63. Baumeister S, Köller M, Dragu A, Germann G, Sauerbier M. Principles of microvascular reconstruction in burn and electrical burn injuries. Burns 2005;31:92-8.

64. Meier K, Nanney LB. Emerging new drugs for scar reduction. Expert Opin Emerg Drugs 2006;11:39-47.

65. Pakyari M, Farrokhi A, Maharlooei MK, Ghahary A. Critical role of transforming growth factor beta in different phases of wound healing. Adv Wound Care (New Rochelle) 2013;2:215-24.

66. RD Mag (2011). Juvista Fails Late-Stage Trial. Available from: https://www.rdmag.com/news/2011/02/juvista-fails-late-stage-trial. [Last accessed on 5 Jun 2019]

67. So K, McGrouther DA, Bush JA, et al. Avotermin for scar improvement following scar revision surgery: a randomized, double-blind, within-patient, placebo-controlled, phase II clinical trial. Plast Reconstr Surg 2011;128:163-72.

68. Sun ZL, Feng Y, Zou ML, et al. Emerging role of IL-10 in hypertrophic scars. Front Med (Lausanne) 2020;7:438.

69. ClinicalTrials.gov [Internet]. Bethesda (MD): National Library of Medicine (US). Investigation into the Scar Reduction Potential of Prevascar (Interleukin-10). Available from: https://www.clinicaltrials.gov/ct2/show/study/NCT00984646. [Last accessed on 20 Dec 2020]

70. Kieran I, Taylor C, Bush J, et al. Effects of interleukin-10 on cutaneous wounds and scars in humans of African continental ancestral origin. Wound Repair Regen 2014;22:326-33. 
71. Doersch KM, DelloStritto DJ, Newell-Rogers MK. The contribution of interleukin-2 to effective wound healing. Exp Biol Med (Maywood) 2017;242:384-96.

72. Januszyk M, Wong VW, Bhatt KA, et al. Mechanical offloading of incisional wounds is associated with transcriptional downregulation of inflammatory pathways in a large animal model. Organogenesis 2014;10:186-93.

73. Wong VW, Paterno J, Sorkin M, et al. Mechanical force prolongs acute inflammation via T-cell-dependent pathways during scar formation. FASEB J 2011;25:4498-510.

74. Gurtner GC, Dauskardt RH, Wong VW, et al. Improving cutaneous scar formation by controlling the mechanical environment: large animal and phase I studies. Ann Surg 2011;254:217-25.

75. Wong VW, Rustad KC, Akaishi S, et al. Focal adhesion kinase links mechanical force to skin fibrosis via inflammatory signaling. Nat Med 2011;18:148-52.

76. Ma K, Kwon SH, Padmanabhan J, et al. Controlled delivery of a focal adhesion kinase inhibitor results in accelerated wound closure with decreased scar formation. J Invest Dermatol 2018;138:2452-60.

77. Li Z, Maitz P. Cell therapy for severe burn wound healing. Burns Trauma 2018;6:13.

78. Sheckter CC, Meyerkord NL, Sinskey YL, Clark P, Anderson K, Van Vliet M. The optimal treatment for partial thickness burns: a costutility analysis of skin allograft vs. topical silver dressings. J Burn Care Res 2020;41:450-6.

79. Spiekstra SW, Breetveld M, Rustemeyer T, Scheper RJ, Gibbs S. Wound-healing factors secreted by epidermal keratinocytes and dermal fibroblasts in skin substitutes. Wound Repair Regen 2007;15:708-17.

80. Blanpain C, Fuchs E. Epidermal stem cells of the skin. Annu Rev Cell Dev Biol 2006;22:339-73.

81. Chua AW, Khoo YC, Tan BK, Tan KC, Foo CL, Chong SJ. Skin tissue engineering advances in severe burns: review and therapeutic applications. Burns Trauma 2016;4:3.

82. Caplan AI, Dennis JE. Mesenchymal stem cells as trophic mediators. J Cell Biochem 2006;98:1076-84.

83. Duscher D, Barrera J, Wong VW, et al. Stem cells in wound healing: the future of regenerative medicine? A mini-review. Gerontology 2016;62:216-25.

84. Jiang D, Scharffetter-Kochanek K. Mesenchymal stem cells adaptively respond to environmental cues thereby improving granulation tissue formation and wound healing. Front Cell Dev Biol 2020;8:697.

85. Chen FG, Zhang WJ, Bi D, et al. Clonal analysis of nestin(-) vimentin(+) multipotent fibroblasts isolated from human dermis. $J$ Cell Sci 2007; 120:2875-83.

86. Vander Beken S, de Vries JC, Meier-Schiesser B, et al. Newly defined ATP-binding cassette subfamily B member 5 positive dermal mesenchymal stem cells promote healing of chronic iron-overload wounds via secretion of interleukin-1 receptor antagonist. Stem Cells 2019;37:1057-74.

87. Tredget EE, Shankowsky HA, Pannu R, et al. Transforming growth factor-beta in thermally injured patients with hypertrophic scars: effects of interferon alpha-2b. Plast Reconstr Surg 1998;102:1317-28; discussion 1329-30.

88. Wang J, Chen H, Shankowsky HA, Scott PG, Tredget EE. Improved scar in postburn patients following interferon-alpha2b treatment is associated with decreased angiogenesis mediated by vascular endothelial cell growth factor. J Interferon Cytokine Res 2008;28:423-34.

89. Kwon SH, Barrera JA, Noishiki C, et al. Current and emerging topical scar mitigation therapies for craniofacial burn wound healing. Front Physiol 2020;11:916.

90. Tredget E, Ferland-Caron G, Kwan P, Wong J. 55 The advantages of fasciocutaneous free tissue transfers for the management of postburn scar contractures. J Burn Care Res 2019;40:S38-9.

91. Hsieh JC, Joshi CJ, Wan R, Galiano RD. The northwestern abdominoplasty scar model: a tool for high-throughput assessment of scar therapeutics. Adv Wound Care (New Rochelle) 2020;9:396-404. 